\section{THE RETURN OF THE DOCTOR*}

\section{BY}

\section{H. S. SOUTTAR, C.B.E., M.Ch., F.R.C.S. President of the British Medical Association}

I am confident that I shall meet with general support if I say that the most important problem facing our profession at the present time is the return of medical men from the Forces. It presents two aspects-their release from the Forces and their establishment in practice-and as both these aspects have engaged the attention of the Association for many months I felt that they would form an appropriate subject for a short presidential address. Both aspects involve problems of the greatest complexity to which I can refer only in the briefest outline, but I hope to be able to convince you that these problems are being attacked with the whole power of the Association and that with the good will of all of us they will be solved.

\section{Classes for Release}

Release from the Forces must follow the plan laid down for demobilization in general and falls into two classes: Class $\mathbf{A}$ being the general routine, Class B dealing with special cases. So far as is possible releases should be in Class A, which depends entirely on age and length of service, for any departure from this means that men will be delayed from release in their proper category. Even, however, where a category is due for release, and particularly in the case of specialists, it may be impossible to effect this without substitution. For this reason it is imperative that the recruitment of young practitioners should continue, and that all the available specialists up to the age of 35 , or in some cases even 40 , who have not already served in the Forces should be prepared to take their turn.

In Class $B$ release may be obtained for those who are urgently needed for work of national importance-in some cases for civilian needs of extreme urgency, in others for the teaching staffs required for the training of students, both undergraduate and postgraduate. These must, however, be jealously guarded, as a large number of releases out of turn in Class B means a delay in Class A. Released doctors will fall into three classes.

Class I consists of those who joined the Forces soon after qualification. In general these men have held a short hospital appointment, but before joining up they had only a very limited clinical experience, and they require further experience under supervision before engaging in practice. Others in this group were on their way to a university degree, but were prevented by recruitment from achieving it. It is the intention of the Government that for all these there should be available hospital appointments carrying a salary of $£ 350$ a year and all found, and with special family allowances for those who require it. Such an appointment held for six months, with its opportunities of clinical experience under skilled supervision, would be of inestimable value at such a critical moment in a young doctor's career. If he wishes to go into practice it will give him the opportunity of looking round and finding a congenial opening ; if he wishes to take a higher degree it puts him well on the way towards this. It is estimated that the number of individuals in this class is now about 10,000 , but, of course, they will only appear in limited numbers as demobilization proceeds.

Class II consists of those who were engaged in general practice before recruitment. Naturally their first anxiety will be to get back to their practices, and to this they will undoubtedly be urged by their overworked colleagues. Many of them will, however, feel the need for refresher courses so that they may regain their clinical touch in civilian work, which is so utterly different from work in the Army, and so that they may learn something of recent advances in medical science. The Government offers a completely inadequate period of two weeks, but they agree that the refresher course may be taken at any time within a year of release, that travelling and subsistence expenses will be paid, and that the cost of employing a locum will be provided if necessary. Whatever the views of the Government, we hope that the hospitals will see that adequate courses of at least a month are provided, and that these are so arranged

* A brief address on his election to the Presidency of the Association at the Annual General Meeting on July 25. as to meet in every way what is needed. The urgent need for our future medical service is to be efficient. One may indeed hope that such refresher courses may only be a starting-point of a great future system of postgraduate education in which all of us will share, and that they may initiate the close co-operation between our hospitals and general practice to which we look forward in the future.

Class III consists of those who are aiming at a specialist career and who wish to pursue it on their release. For them posts of the registrar type will be found, especially in the teaching hospitals, and they will be paid $£ 550$ a year with board and lodging. Arrangements for these appointments-and this applies also to Classes I and II-will be made through the universities, and it is already generally agreed that the experience which the candidate has already gained will be counted towards the requirements for entry to the higher examinations, and will receive consideration from those whose duty it is to conduct examinations.

\section{Back to Practice}

There still remains the problem of establishment in practice, and here the responsibility shifts from Government Departments and examining bodies, and must be accepted by ourselves. It is we who must make the path smooth for the returning doctor, and more especially for those who are entering general practice for the first time. Some fortunate men will return to a share in an established practice, where they will be welcomed with more than open arms. Some 10,000, however, will have to find openings, and without our help they may not find it too easy. Much careful study has been given to their problems, and they will find the Association ready with full information of the openings available and prepared to give not only advice but very substantial help. Assistantships can be arranged at once, and if these mature into a mutual desire for partnership provision can be made for the necessary finance. If, for example, a doctor without capital desires to purchase a practice arrangements can be made through the services of the Medical Insurance Agency by which he can obtain the whole sum required at a low rate of interest. Such an arrangement offers a double advantage, for not only does it benefit the young practitioner setting out on his career, but it also relieves the anxieties of the older man who has held the fort so magnificently against all the odds of age and overwork until the young man could return.

There will still remain difficult cases in which all the help that can be given from official sources must be quite inadequate. To meet such cases in the early days of the war we instituted a Medical War Relief Fund, which has reached the sum of $£ 54,000$, of which $£ 24,000$ has already been spent in relief. After what I have seen for myself of the amazing relief which has been brought to individual cases by this fund I would urge that now is the moment to raise it to an amount commensurate with the occasion, and that we should use this opportunity to prove to those who have given such great service to their country that we appreciate what they have done and will give them all the help that they have so fully earned.

Here is no question of charity; rather is it the payment of a debt that we owe ; but most of all we should be setting our seal to the brotherhood of our profession and to our determination that those who have suffered through no fault of their own shall be able to turn for support to those of us who have been more fortunate. I should like to see the fund raised to such a sum as will ensure that we shall be able to give to all those who need it the adequate and unstinted help which I know we all desire. Ours is a great profession. Let us see to it that in the years to come it is a great brotherhood.

An educational lecture on oxygen therapy is available to medical superintendents, sister tutors, and other lecturers. It traces the history of oxygen therapy, the principles and applications, and the forms of apparatus in use to-day. The text is supplied in typescript written in a style suitable for presentation to doctors, nurses, and students, and takes about 40 to 45 minutes in all. A series of lantern slides accompanies the text and illustrates the manufacture of oxygen, the installation of oxygen in hospitals, and various types of apparatus used from the most primitive form to the latest design. Details of the lecture-which is loaned without charge-may be had from Oxygenaire Ltd., 8, Duke Street, Wigmore Street, London, W.1. 